\title{
Is minor salivary gland biopsy more than a diagnostic tool in primary Sjögren's syndrome? Association between clinical, histopathological, and molecular features: A retrospective study
}

\author{
Francesco Carubbi, MD ${ }^{\mathrm{a}, 1, *}$, Alessia Alunno, $\mathrm{MD}^{\mathrm{b}, 1}$, Paola Cipriani, MD, $\mathrm{PhD}^{\mathrm{a}}$, \\ Paola Di Benedetto, $\mathrm{PhD}^{\mathrm{a}}$, Piero Ruscitti, $\mathrm{MD}^{\mathrm{a}}$, Onorina Berardicurti, $\mathrm{MD}^{\mathrm{a}}$, \\ Elena Bartoloni, $\mathrm{MD}^{\mathrm{b}}$, Onelia Bistoni, BSc ${ }^{\mathrm{b}}$, Sara Caterbi, $\mathrm{PhD}^{\mathrm{b}}$, Francesco Ciccia, MD, $\mathrm{PhD}^{\mathrm{c}}$, \\ Giovanni Triolo, $\mathrm{MD}^{\mathrm{c}}$, Roberto Gerli, $\mathrm{MD}^{\mathrm{b}}$, Roberto Giacomelli, $\mathrm{MD}, \mathrm{PhD}^{\mathrm{a}}$ \\ a Department of Clinical Science and Biotechnology, Rheumatology Unit, University of L'Aquila, L'Aquila 67100, Italy \\ ${ }^{\mathrm{b}}$ Department of Medicine, Rheumatology Unit, University of Perugia, Perugia, Italy \\ ${ }^{\mathrm{c}}$ Division and Laboratory of Rheumatology, University of Palermo, Palermo, Italy
}

\section{A R T I C L E I N F O}

Keywords:

Sjögren's syndrome

Minor salivary glands

Germinal center

$\mathrm{LT} \alpha$

LT $\beta$

BAFF

CXCR4

CXCL12

CXCR5

CXCL13

CCR7

CCL19

CCL21

\begin{abstract}
A B S T R A C T
Objectives: Several histological scoring systems, including the focus score, performed in minor salivary glands (MSGs) by hematoxylin-eosin (H\&E) staining, have been employed in clinical practice to assess the inflammatory infiltrate and provide the diagnosis of primary Sjögren's syndrome (pSS). Aims of this study were to integrate different scoring systems and identify potential differences in the molecular profile of lymphoid cytokines related to germinal center (GC) formation and clinical subsets in pSS. Methods: Overall, 104 pSS patients and 40 subjects with sicca non-pSS were retrospectively evaluated. MSG biopsies were evaluated by H\&E and immunofluorescence to assess histological pattern, Chisholm and Mason grading system, Tarpley score, a grading for the severity of inflammatory infiltrate, T-/B-cell segregation, and the presence of GC. MSGs from 50 pSS patients and 30 sicca non-pSS patients were processed by real-time PCR to assess LT $\alpha$, LT $\beta$, BAFF, CXCR4, CXCL12, CXCR5, CXCL13, CCR7, CCL19, and CCL21.

Results: GCs presence was associated with anti-Ro/SSA and anti-La/SSB antibodies, hypergammaglobulinemia, salivary gland swelling, higher Tarpley score and focus score, and extraglandular involvement but, at multivariate analysis, only extraglandular involvement was independently associated to GC. pSS patients displayed higher level of all cytokines compared to those with sicca symptoms. $\mathrm{GC}^{+}$pSS patients displayed higher level of all cytokines compared to those $\mathrm{GC}^{-}$.

Conclusions: Our study demonstrates that different histopathological patterns, including GC presence, reflect different cytokine expression and different clinical subsets. We believe that the combined immunofluorescence/molecular approach in MSGs would help to tailor diagnostic and therapeutic approach for different subsets of pSS patients.
\end{abstract}

(c) 2014 Elsevier Inc. All rights reserved.

\section{Introduction}

Primary Sjögren's syndrome (pSS) is a systemic autoimmune disease characterized by mucosal dryness and, in at least one-third of patients, by extraglandular involvement, with musculoskeletal,

Department and institution to which the work should be attributed: Department of Clinical Science and Biotechnology, Rheumatology Unit, University of L'Aquila, L'Aquila, Italy.

* Corresponding author.

E-mail address: francescocarubbi@libero.it (F. Carubbi).

${ }^{1}$ These authors contributed equally to this article. cutaneous, renal, pulmonary, or neurological manifestations [1]. Furthermore, 5\% of patients may develop lymphoma, mainly the mucosa-associated lymphoid tissue (MALT) non-Hodgkin lymphoma (NHL), which represents the most severe complication of the disease [2,3]. At present, although several pathogenic mechanisms have been suggested trying to understand the clinical heterogeneity of the disease, several aspects remain unknown. In this setting, putative biomarkers able to identify different clinical subsets and eventually disease outcome are still lacking.

Minor salivary glands (MSGs) of patients with pSS show a focal lymphocytic sialadenitis (FLS) characterized by the presence of one or more dense aggregates with 50 or more lymphocytes, usually 
located in the perivascular or periductal areas, in $4 \mathrm{~mm}^{2}$ of glandular tissue [4]. In addition to FLS, different morphologic patterns of chronic inflammation commonly occur in MSG biopsy specimens: non-specific chronic sialadenitis (NSCS) and sclerosing chronic sialadenitis (SCS) [5]. Different histological scores have been employed to describe glandular involvement during pSS [6-10], and as far as MSGs histology is concerned, its diagnostic role is widely accepted and currently considered the "gold standard." Indeed, MSG biopsy is considered 1 of the 4 objective criteria of American-European Consensus Group's classification and 1 of the 3 objective criteria of American College of Rheumatology's classification for pSS [11,12].

However, although the practical role of the biopsy is commonly accepted, a recent meta-analysis pointed out that a very low number of studies are available to support its diagnostic usefulness [13], suggesting that further studies aimed to confirm the diagnostic role of MSG biopsy and possibly to correlate MSGs histopathology with clinical picture are needed.

The spectrum of MSG histopathological damage ranges from mild to diffuse infiltrates with progressive loss of normal glandular tissue. T-cells predominate in mild lesions, whereas B-cells are the most represented cell subset in the advanced lesions, with a decrease in the percentage of macrophages and an increased percentage of DCs [14-16].

Infiltrating lymphocytes are often organized into tertiary ectopic lymphoid structures, showing a network including specific segregated T- and B-cell zones associated to follicular dendritic cells (fDCs). Some of these ectopic lymphoid structures mirror classical germinal centers (GCs) $[17,18]$. This organization in lymphoid GC-like structures is well documented in pSS and can be detected in one-third of patients [19]. GC-like structures contain the machinery required for antibody production, and it has been reported that pSS-specific autoantibodies may be directly generated by plasma cells located in MSG-organized infiltrates $[19,20]$. GC-like structures in MSGs are associated with (i) higher frequency of extraglandular manifestations, (ii) higher focus score, (iii) hypergammaglobulinemia, (iv) higher levels of circulating rheumatoid factor, and (v) higher prevalence of circulating anti-Ro (SSA)/anti-La (SSB) autoantibodies in sera. Furthermore, it has been suggested that GC-like structures may correlate with later lymphoma development [21-23]. Moreover, patients developing GC-like infiltrates display a different genetic, serological, and glandular cytokine profile when compared to those without GCs [24-27].

The pathogenesis of pSS is a complex mechanism strongly mediated by different effectors cells and their products. It is now well established that T-cells largely infiltrate affected salivary glands leading to an upregulation of Th1- and Th17-associated cytokines. Besides these proinflammatory mediators, including interferon $\alpha$ and $\gamma$, tumor necrosis factor $\alpha$, and interleukin (IL)-12 and IL-18, other cytokines involved in T- and B-cell activation and autoantibody production, such as IL-6, are overexpressed. In contrast, pivotal anti-inflammatory mediators, including IL-4 and transforming growth factor $\beta$, are expressed at low levels [28]. In this contest, Th17 cells represent the major source of several proinflammatory cytokines, such as IL-17, IL-21 and IL-22 [29], and the IL-23/IL-17 pathway is known to play a central role in autoimmunity and chronic inflammation in pSS [30].

Although the presence, and sometimes predominance, of T cells in salivary gland infiltrates underscores their potential contribution to the pathogenesis of pSS [29,31-33], growing evidence suggest a central role of B cells in the development of the disease [34]. Indeed, B lymphocyte hyperactivity and prolonged B-cell survival as well as their aberrant activity may lead to the development of NHL [2,35].

B-cell activating factor (BAFF) is involved in B-cell survival and humoral immune responses and plays a critical role in B-cell homeostasis [36]. BAFF overexpression, observed in serum, saliva, and MSGs of pSS patients, particularly those with GCs, rescues auto-reactive cells from depletion in the periphery, leading to higher number of mature auto-reactive B cells [24,37-41].

Evidence from animal models and patients with pSS demonstrated that the formation and maintenance of tertiary lymphoid tissues are critically dependent on ectopic expression of lymphotoxins and homeostatic chemokines such as CXCL13, CXCL12, CCL19, and CCL21 and interaction with their specific receptors, CXCR5, CXCR4, and CCR7, respectively. These key molecules are produced during chronic inflammation by several cell types, including resident epithelial, stromal, and endothelial cells, as well as different subsets of infiltrating immune cells [17,42].

The lymphotoxin-alpha (LT $\alpha)$ and lymphotoxin-beta (LT $\beta)$ pathways have also been associated with the presence of ectopic lymphoid structures at the sites of chronic inflammation in several autoimmune diseases [43]. Furthermore, when compared with the inflammatory process of non-specific sialadenitis, salivary glands of patients with pSS have been found to express a unique profile of cytokines, including a striking overexpression of CXCL13 and, to a lesser degree, CXCL12 [44-48]. Furthermore, CXCL12-CXCR4 and CXCL13-CXCR5 interactions have been suggested to be involved in B-cell deregulation, preferential migration of CXCR4- and CXCR5expressing $\mathrm{CD} 27+$ memory B-cells into the inflamed salivary glands, the development of ectopic GC-like structures as well as the peripheral B-cell abnormalities [49,50].

CCL21 is progressively increased with the gradual acquisition of lymphoid features in pSS salivary glands [44], while animal models of MSG inflammation show the role of CCR7/CCL19-CCL21 axis in the inducible ectopic lymphoid tissue formation [51]. The presence of CCL19/CCL21 allows the homing of T-cells, mature DCs, and to a lesser extent, of CCR7-expressing naïve B-cells to secondary lymphoid organs from the systemic circulation [52-54].

Although histological studies, and in consequence pSS diagnosis, are mainly based on hematoxylin-eosin (H\&E) staining, new approaches, such as immunofluorescence or molecular biology assays, allow to stratify pSS patients according to other variables including GC presence and cytokine expression. Such evaluations might represent a powerful tool to predict pSS clinical picture and possibly the disease prognosis in clinical practice.

Taken the well-known role of the aforementioned molecules in the organization of MSG lymphoid infiltrates and the lack of a correlation between histological patterns and clinical picture, we investigated the relationship between the characteristic of the immune infiltrate, including the presence of GC-like structures, the molecular expression of different cytokines, and laboratory and clinical features in a large cohort of pSS patients.

\section{Methods}

\section{Study population}

Overall, 104 pSS patients (98 females and 6 males) referring to the Rheumatology Unit, University of L'Aquila, Italy, or to the Rheumatology Unit, University of Perugia, Italy, from September 1, 2009 to December 31, 2013 were retrospectively evaluated. All patients were over 18 years old, fulfilled the American-European consensus criteria for pSS, including histopathologic criteria [11], and we excluded patients with SS associated to one or more systemic-/organ-specific autoimmune diseases. A total of 40 subjects with sicca symptoms, of whom (i) 20 (16 women and 4 men) with normal MSGs and absence of any clinical and serological feature of pSS and (ii) 20 (15 women and 5 men) without any clinical and serological feature of pSS, but showing different grade of MSG inflammation (NSCS) without FLS, acted as controls. Both pSS patients and subjects with sicca symptoms did not display 
current or previous hepatitis $\mathrm{C}$ infection. All clinical data were recorded at the time of diagnosis. The whole study was approved by the local Ethic Committees. Written informed consent was obtained from all subjects, in accordance with the declaration of Helsinki.

\section{Histological analysis of MSG biopsies}

Labial MSG biopsies were obtained from all patients and controls at the time of biopsy collection for differential diagnosis of sicca symptoms, according to international guidelines. All sections were randomly analyzed by 2 expert observers, blinded to clinical and molecular data. Each sample was independently evaluated, and any discrepancies were resolved by consensus.

For histological evaluation, H\&E-stained sections were assessed as follows: (i) the histological pattern (normal, NSCS, or FLS) [5]; (ii) the Chisholm and Mason grading system (grades 0-4) [6]; (iii) the Tarpley score (scores 0-4) [7]; (iv) a grading for the severity of inflammatory infiltrate (grades $1-5)[9,10]$; and (v) the focus score, assessing the number of foci $/ 4 \mathrm{~mm}^{2}$ (a focus is defined as an aggregate including at least 50 mononuclear cells) [8]. A biopsy was considered GC positive $\left(\mathrm{GC}^{+}\right)$if displaying at least one focus with lymphoid-like organization within normal MSG tissue. Focal infiltrates without lymphoid organization were classified as GC negative $\left(\mathrm{GC}^{-}\right)$[27].

Both cellular infiltrate and lymphoid organization were assessed by immunofluorescence staining of sequential sections with monoclonal antibodies recognizing CD3, CD20, and CD21 (all provided by DakoCytomation, Glostrup, Denmark). Formalin-fixed and paraffin-embedded sections, measuring $3 \mu \mathrm{m}$ in thickness, were dewaxed and rehydrated. All sections underwent hightemperature antigen retrieval using Target Retrieval Solution (Dako, Glostrup, Denmark) for $35 \mathrm{~min}$ at $95^{\circ} \mathrm{C}$, except for sections stained with anti-CD21, which underwent proteolytic digestion for 7 min at $37^{\circ} \mathrm{C}$ using proteinase $\mathrm{K}$ (Dako, Glostrup, Denmark).

For sections stained with anti-CD3 or anti-CD21, we performed nonspecific binding blocking (Protein Block Serum-Free ready-touse; Dako, Glostrup, Denmark). For sections stained with antiCD20, we also performed endogenous biotin blocking (AvidinBiotin blocking system; Vector Laboratories, Burlingame, CA).

To assess T-/B-cell segregation, sections were double stained with anti-CD3/anti-CD20 antibodies. Monoclonal mouse antihuman CD3 (dilution 1:50) was incubated for $1 \mathrm{~h}$ at room temperature in wet chamber, followed by an incubation of $30 \mathrm{~min}$ with secondary antibody goat anti-mouse/Alexa Fluor-555 (1:100) (Invitrogen, Paisley, UK). Subsequently, monoclonal mouse antihuman CD20 (1:20) incubation was performed for $1 \mathrm{~h}$ at room temperature in wet chamber, followed by 30 min incubation with biotin goat anti-mouse IgG (1:100) (Biolegend, San Diego, CA) and 30 min incubation with streptavidin/Alexa Fluor 488 (1:200) (Invitrogen, Paisley, UK).

To detect fDC networks and identify GCs, sections were incubated overnight at $4^{\circ} \mathrm{C}$ with monoclonal mouse anti-human CD21 (1:20) followed by an incubation of $30 \mathrm{~min}$ with secondary antibody goat anti-mouse/Alexa Fluor 488 (1:100) (Invitrogen, Paisley, UK).

All sections were counterstained with 4',6-diamidino-2phenylindole (DAPI; $1: 1000$ ) for $10 \mathrm{~min}$, and slides were mounted with Mowiol 4-88 (Sigma-Aldrich, Milan, Italy). Images were acquired using an Olympus BX53 fluorescence microscope with cellSens software (Olympus America Inc., Center Valley, PA).

$R N A$ isolation and quantitative real-time polymerase chain reaction (qRT-PCR)

Of 104 MSG specimens obtained from pSS patients, 50 were stored for molecular analysis. To avoid any biases due to B-cell monoclonal expansion, we excluded from molecular analysis the specimens obtained from the 2 pSS patients in which the diagnosis of B-cell lymphoma was reported. A total of 10 normal MSGs and 20 MSGs with NSCS acted as control groups. Total RNA was extracted from MSGs using TRIZOL (SIGMA, St. Louis, MO) and reverse transcribed into complementary DNA (cDNA) with the ThermoScript reverse transcription-polymerase chain reaction system (Invitrogen, Carlsbad, CA). The qRT-PCR was performed by using SYBR green kits and Taqman gene expression assays (Applied Biosystems, Utrecht, the Netherlands). Results were analyzed after 40 cycles of amplification using the ABI 7500 Fast Real Time PCR System (Applied Biosystems, Utrecht, the Netherlands). Primers were designed on the basis of the reported sequences (PrimerBank NCBI): LT $\alpha-5^{\prime}$-ATGACACCACCTGAACGTCTC-3' (forward) and 5'-CTCTCCAGAGCAGTGAGTTCT-3' (reverse); LT $\beta$ - 5'-GACGAAGGAACAGGCGTTTCT-3' (forward) and 5'-GTAGCCGACGAGACAGTAGAG-3' (reverse); $\beta$-actin-5'-CCTGGCACCCAGCACAAT-3' (forward) and 5'-AGTACTCCGTGTGGATCGGC-3' (reverse); CXCR5-5'-CACGTTGCACCTTCTCCCAA-3' (forward) and 5'-CGCCACATGGTAGAGGAATCG-3' (reverse); CXCL13-5'-GCTTGAGGTGTAGATGTGTCC-3' (forward) and 5'-CGATCAATGAAGCGTCTAGGGAT-3' (reverse); CXCR4-5'-GACTTGTGGGTGGTTGTG-3' (forward) and 5'-AGGATGAGGATGACTGTGG-3' (reverse); CXCL12-5'-GAGCCAACGTCAAGCATCTC-3' (forward) and 5'-CAATGCACACTTGTCTGTTG-3 (reverse); BAFF-5'-TTGAGTCTGGTGACTTTGTTTCG-3' (forward) and 5'-GCAAGTTGGAGTTCATCTCCTT-3' (reverse); CCR7-5'-TGAGGTCACGGACGATTACAT-3' (forward) and 5'-GTAGGCCCACGAAACAAATGAT-3' (reverse); CCL19-5'-CTGCTGGTTCTCTGGACTTCC-3' (forward) and 5'-AGGGATGGGTTTCTGGGTCA-3' (reverse); and CCL21-5'GTTGCCTCAAGTACAGCCAAA-3' (forward) and 5'-ACAGGATAGCTGGGATGG-3' (reverse).

\section{Statistical analysis}

Data analysis was performed using IBM-SPSS version 13.0 (IBM, Armonk, NY). Inter-observer agreement with respect to the assessment of inflammation before the consensus meeting of the 2 observers was expressed as weighted Cohen's $\kappa$. Mann-Whitney $U$ test or Kruskal-Wallis test with Dunn's test for multiple comparison was employed to compare cytokine expression among different groups. Fisher exact test was employed to compare frequencies between pSS and controls or among pSS patient subgroups. Binary logistic regression was used to identify possible association between clinical and serological features and the presence of GC. The significance level was 2 sided and set at $p<0.05$.

\section{Results}

\section{Demographic and clinical characteristics of pSS patients}

Table 1 summarizes clinical, serological, and histological features of pSS patients. All data were recorded at the time of diagnosis. Our cohort included 98 females and 6 males with a mean age, at diagnosis, of $52 \pm 12$ years. Of 104 patients, 92 (88\%) complained ocular symptoms while 89 (86\%) experienced oral symptoms. In $22(21 \%)$ patients, salivary gland swelling was reported, and in 73 (70\%) patients, extraglandular involvement occurred. Over $50 \%$ of patients displayed anti-Ro/SSA antibodies and, of these, $25 \%$ displayed both anti-Ro/SSA and anti-La/SSB antibodies.

\section{Histological analysis of MSG biopsies}

As far as the histological patterns are concerned, Table 2 summarizes the scoring systems employed in the study. 
Table 1

Clinical, laboratory, and histological characteristics of patients with primary Sjogren's syndrome

\begin{tabular}{|c|c|c|c|c|}
\hline & pSS total $(n=104)$ & $\mathrm{GC}^{+}(n=58)$ & $\mathrm{GC}^{-}(n=46)$ & $p$ Value \\
\hline Mean age at diagnosis (years) & 52 & 49 & 55 & 0.02 \\
\hline Proportion of female patients (\%) & $98(94)$ & $56(96)$ & $42(91)$ & ns \\
\hline Ocular symptoms (\%) & $92(88)$ & $52(90)$ & $40(87)$ & ns \\
\hline Oral symptoms (\%) & $89(86)$ & $49(84)$ & $40(87)$ & ns \\
\hline Salivary gland swelling (\%) & $22(21)$ & $19(33)$ & $3(6)$ & 0.001 \\
\hline Extraglandular manifestations (\%) & $73(70)$ & $41(71)$ & $32(70)$ & ns \\
\hline Lymphadenopathy involvement (\%) & $27(26)$ & $18(31)$ & $9(20)$ & ns \\
\hline Articular involvement (\%) & $47(45)$ & $28(48)$ & $19(41)$ & ns \\
\hline Cutaneous involvement (\%) & $12(11)$ & $7(12)$ & $5(11)$ & ns \\
\hline Pulmonary involvement (\%) & $12(11)$ & $6(10)$ & $6(13)$ & ns \\
\hline Renal involvement (\%) & $4(4)$ & $2(3)$ & $2(4)$ & ns \\
\hline Muscular involvement (\%) & $2(2)$ & $1(2)$ & $1(2)$ & ns \\
\hline Peripheral nervous system involvement (\%) & $10(10)$ & $5(9)$ & $5(11)$ & ns \\
\hline Central nervous system involvement (\%) & $5(5)$ & $1(2)$ & $4(9)$ & ns \\
\hline Gastrointestinal involvement (\%) & $14(13)$ & 10 (17) & $4(9)$ & ns \\
\hline Raynaud's phenomenon (\%) & $34(33)$ & $18(31)$ & $16(35)$ & ns \\
\hline Leukopenia (\%) & $29(28)$ & $17(29)$ & $12(26)$ & ns \\
\hline Hypergammaglobulinemia (\%) & $34(33)$ & $28(48)$ & $6(13)$ & 0.0001 \\
\hline Hypocomplementemia (\%) & $12(11)$ & $8(14)$ & $4(9)$ & ns \\
\hline Lymphoma (\%) & $2(2)$ & $2(3)$ & $0(0)$ & ns \\
\hline Antinuclear antibody (ANA) (\%) & $80(77)$ & $51(88)$ & $29(63)$ & 0.004 \\
\hline Anti-Ro (SSA) antibody (\%) & $58(56)$ & $49(84)$ & $9(20)$ & $<0.0001$ \\
\hline Anti-La (SSB) antibody (\%) & $28(27)$ & $26(45)$ & $2(4)$ & $<0.0001$ \\
\hline Anti-Ro (SSA) and anti-La (SSB) antibody (\%) & $26(25)$ & $25(43)$ & $1(2)$ & $<0.0001$ \\
\hline Rheumatoid factor (\%) & $33(32)$ & $23(40)$ & $10(22)$ & 0.05 \\
\hline Mean focus score & 2 & 2 & 1 & $<0.0001$ \\
\hline FLS $(\%)$ & $104(100)$ & $58(100)$ & $46(100)$ & ns \\
\hline Chisholm and Mason grade $3(\%)$ & $42(40)$ & $10(17)$ & $32(70)$ & $<0.0001$ \\
\hline Chisholm and Mason grade 4 (\%) & $62(60)$ & $48(83)$ & $14(30)$ & $<0.0001$ \\
\hline Tarpley score $1(\%)$ & $50(48)$ & $14(24)$ & $36(78)$ & $<0.0001$ \\
\hline Tarpley score $2(\%)$ & $12(11)$ & $6(10)$ & $6(13)$ & ns \\
\hline Tarpley score $3(\%)$ & $21(20)$ & $18(31)$ & $3(6)$ & 0.003 \\
\hline Tarpley score $4(\%)$ & $21(20)$ & $20(34)$ & $1(2)$ & $<0.0001$ \\
\hline Severity of inflammatory infiltrate 5 (\%) & $104(100)$ & $58(100)$ & $46(100)$ & ns \\
\hline
\end{tabular}

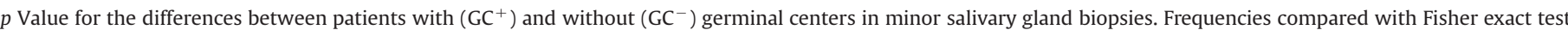
and continuous variables with Mann-Whitney $U$ test. ns, not significant; FLS, focal lymphocytic sialadenitis.

Inter-observer agreement on both the assessment of inflammation and the histological diagnosis of pSS was high (Cohen's $\kappa=0.87$ ). Disagreements were easily resolved by consensus between observers. A total of $42(40 \%)$ patients displayed 1 focus in $4 \mathrm{~mm}^{2}$ of salivary tissue and a Chisholm and Mason grade 3. Conversely, in $62(60 \%)$ patients, the number of foci in $4 \mathrm{~mm}^{2}$ was $>1$, corresponding to a Chisholm and Mason grade 4. According to the different extent of glandular architecture derangement, 50 (48\%) patients displayed a Tarpley score $1,12(11 \%)$ patients a Tarpley score 2, $21(20 \%)$ patients a Tarpley score 3, and $21(20 \%)$ patients a Tarpley score 4. Of 104 patients, 58 (56\%) displayed GC-like structures at the time of diagnosis. MSGs of $\mathrm{GC}^{+}$patients showed a glandular infiltrate with $\mathrm{B} / \mathrm{T}$ compartmentalization and positivity

Table 2

Histological patterns and scoring systems in MSG biopsy

\begin{tabular}{llll}
\hline $\begin{array}{c}\text { Histological } \\
\text { pattern }\end{array}$ & $\begin{array}{l}\text { Chisholm and Mason } \\
\text { grading system }\end{array}$ & $\begin{array}{l}\text { Tarpley } \\
\text { score }\end{array}$ & $\begin{array}{l}\text { Severity of } \\
\text { inflammatory infiltrate }\end{array}$ \\
\hline Normal & 0 & & 1 \\
NSCS & 1 & 0 & 2 \\
& & & 3 \\
SCS & 2 & 1 & 4 \\
FLS & 3 & 2 & 5 \\
& 4 & 3 & \\
& & 4 &
\end{tabular}

NSCS, non-specific chronic sialadenitis; SCS, sclerosing chronic sialadenitis; FLS, focal lymphocytic sialadenitis; MSG, minor salivary gland. For detailed information concerning each scoring system, please refer to the article and corresponding references. for fDCs, while in the majority of $\mathrm{GC}^{-}$patients, the $\mathrm{B} / \mathrm{T}$ compartmentalization was absent. Figure 1 displays representative MSGs of a patient with (A-C) and a patient without (D-F) GC-like structures.

\section{$G C^{+} / G C^{-}$patient analysis}

When pSS patients were divided according to the presence or absence of GC-like structures in MSGs (Table 1), we observed that $\mathrm{GC}^{+}$patients received a diagnosis of pSS at a younger age (49 \pm 12 vs $55 \pm 12$ years, $p=0.02$ ) and experienced more frequently salivary gland swelling compared to those without GC (33\% vs $6 \%$, $p=0.001)$. Furthermore, $\mathrm{GC}^{+}$patients displayed more frequently hypergammaglobulinemia, anti-Ro/SSA antibodies, anti-La/SSB antibodies, the combination of anti-Ro/SSA and anti-La/SSB antibodies (all $p<0.0001$ ), antinuclear antibodies (ANA), and rheumatoid factor $(\mathrm{RF})$ positivity $(p=0.004$ and 0.05 , respectively). To note, $\mathrm{GC}^{+}$subgroup showed a higher prevalence of Tarpley score 3 or 4 ( $p=0.003$ and $<0.0001$, respectively) as well as a higher prevalence of Chisholm and Mason grade $4(p<$ 0.0001 ).

Therefore, we subsequently performed binary logistic regression in order to quantify the strength of the association between GCs and other histological, clinical, and serological variables. As shown in Table 3, patients displaying either anti-Ro/SSA or the association of anti-Ro/SSA and anti-La/SSB antibodies had higher odds ratios (ORs) of having a GC-like structure (13.5 and 98, respectively; both $p<0.0001$ ). An association with GCs was also observed concerning hypergammaglobulinemia ( $\mathrm{OR}=6.3$ ), salivary gland swelling $(\mathrm{OR}=7.2)$ (both $p<0.01)$, and Tarpley score 


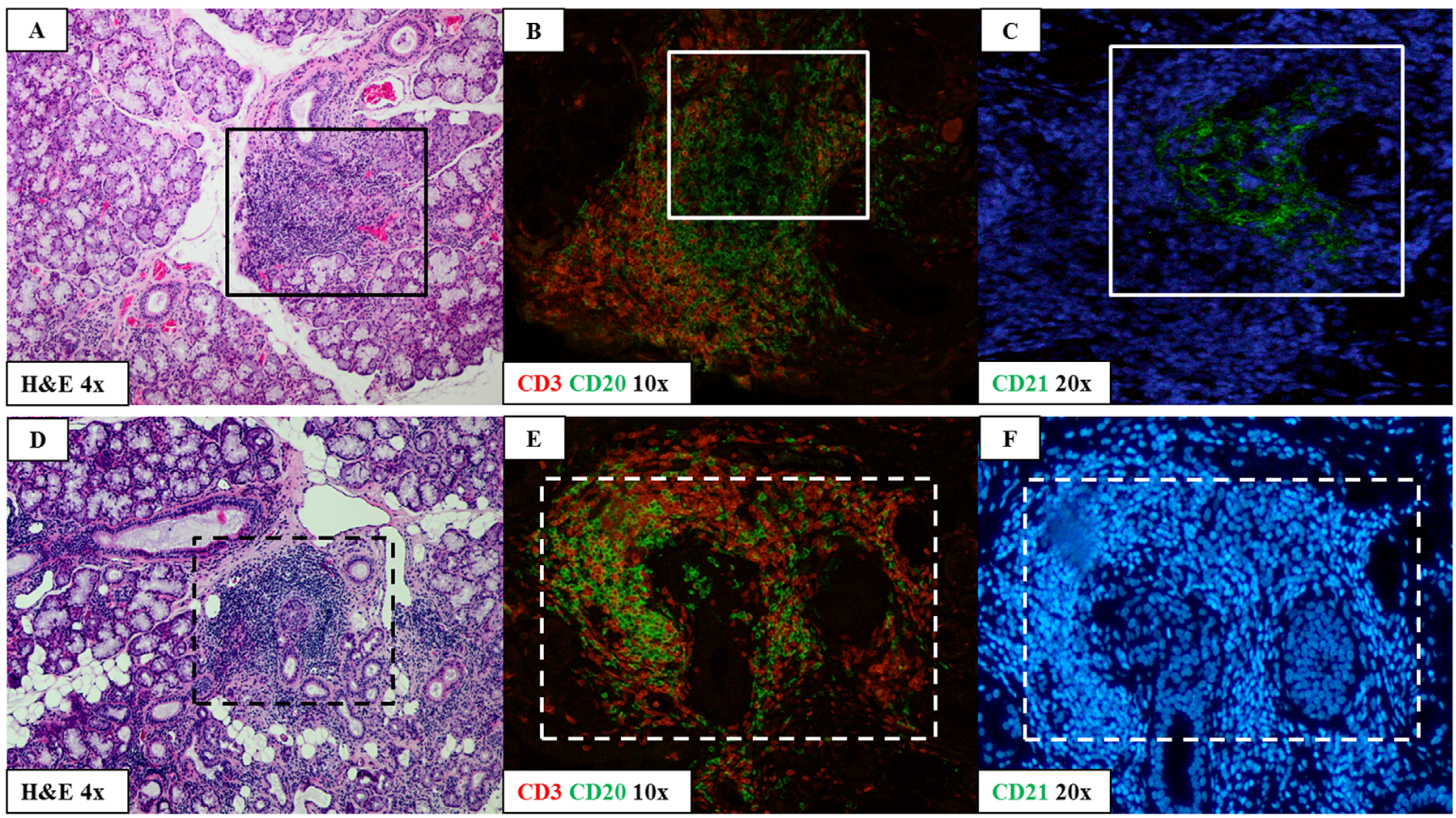



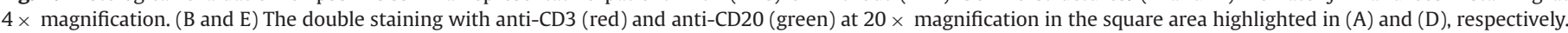

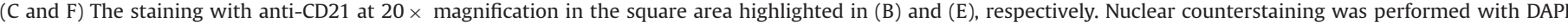
( $\mathrm{B}, \mathrm{C}, \mathrm{E}$, and F). (For interpretation of the references to colour in this figure legend, the reader is referred to the web version of this article.)

and focus score (both ORs $=4, p<0.0001$ ). To note, in $\mathrm{GC}^{+}$ patients, a significant association with extraglandular involvement was also highlighted ( $\mathrm{OR}=4.5, p=0.005)$. When all these variables were analyzed by multivariate analysis, we observed that only the extraglandular involvement was independently associated to $\mathrm{GC}$ presence $(\mathrm{OR}=5.3, p<0.004$ ), thereby confirming the increased risk to develop a more severe disease in $\mathrm{GC}^{+}$patients.

\section{Molecular analysis of MSG biopsies}

Subsequently, we moved to assess cytokines and chemokines known to be involved, not only in the induction and development of glandular damage in pSS, but also in ectopic lymphoneogenesis and GC formation. As displayed in Supplementary Table S1, the 50 pSS patients whose MSGs were available for molecular analysis resembled clinical, serological, and histological features of the global study cohort.

A total of 30 subjects with sicca symptoms and either normal MSG or NSCS were used as controls. As depicted in Figure 2A, pSS patients displayed higher levels of all tested cytokines compared to normal MSGs (all $p<0.0001$ ). A similar behavior was observed when pSS patients where compared to subjects with NSCS (all $p<$ 0.0001). No difference was observed between normal MSGs and NSCS MSGs for any of the evaluated cytokines.

According to the severity of inflammatory infiltrate, we stratified subjects with normal MSGs (severity grade 1) and NSCS (severity grade from 2 to 4 ) in order to identify any differences concerning the assessed molecules between these 2 subsets. Figure 2B displays that NSCS cytokine profile does not differ from that of normal MSGs except for CXCL13 which appears higher in subjects with a severity grade of 4 with respect to normal MSGs $(p<0.0001)$. In addition, CXCL13 was more expressed in subjects with severity grade 4 compared to those with severity grades 2 and 3 (both $p<0.05$ ). pSS patients (severity grade 5 ) displayed higher levels of all tested cytokines when compared to normal MSGs (all $p<0.0001$ ). Moreover, pSS patients displayed higher levels of all the tested cytokines, when compared to patients with severity of inflammatory infiltrate grades 2 , 3, and 4 (all $p<0.05$ ).

Table 3

Univariate and multivariate logistic regression analysis of factors associated with the presence of germinal centers

\begin{tabular}{|c|c|c|c|c|c|c|}
\hline \multirow[t]{2}{*}{ Variable } & \multicolumn{3}{|c|}{ Univariate } & \multicolumn{3}{|c|}{ Multivariate } \\
\hline & OR & $95 \% \mathrm{CI}$ & $p$ Value & OR & $95 \% \mathrm{CI}$ & $p$ Value \\
\hline Anti-Ro/SSA antibody ${ }^{a}$ & 13 & $4.4-41$ & $<0.0001$ & 0.7 & $0.4-2.2$ & 0.4 \\
\hline Anti-Ro/SSA and anti-La/SSB antibody ${ }^{a}$ & 98 & $11.7-829$ & $<0.0001$ & 0.6 & $0.3-1.3$ & 0.2 \\
\hline Hypergammaglobulinemia & 6.3 & $2.3-17$ & 0.0003 & 0.6 & $0.2-2.3$ & 0.5 \\
\hline Salivary gland swelling & 7.2 & $1.9-26$ & 0.003 & 2.5 & $0.5-11.6$ & 0.3 \\
\hline Tarpley score & 4 & $2.4-7$ & $<0.0001$ & 0.9 & $0.5-1.9$ & 0.9 \\
\hline Focus score & 4 & $2.1-8$ & $<0.0001$ & 0.8 & $0.4-1.5$ & 0.5 \\
\hline Extraglandular involvement & 4.5 & $1.6-12.6$ & 0.005 & 5.3 & $1.7-16.7$ & 0.004 \\
\hline
\end{tabular}

OR, odds ratio; $\mathrm{CI}$, confidence interval.

a Compared to pSS patients with negative anti-Ro/SSA and anti-La/SSB antibodies. 
A



B

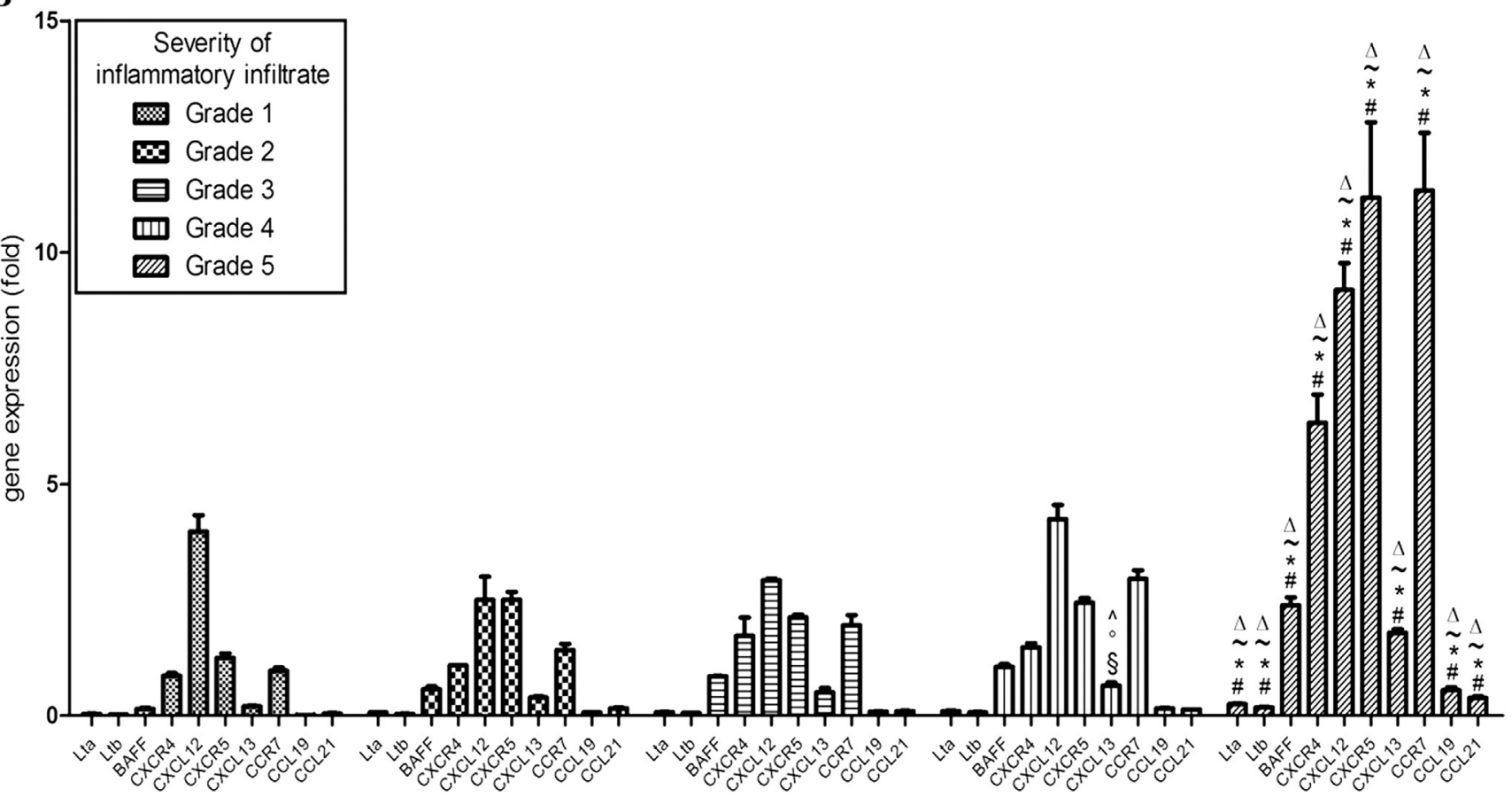

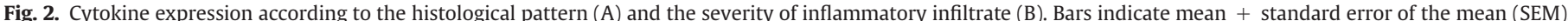

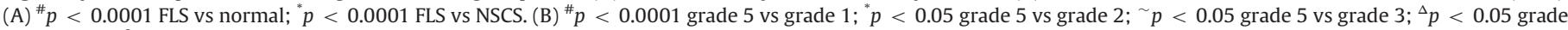

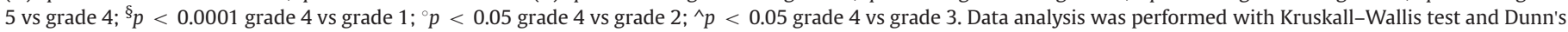
test for multiple comparison. FLS, focal lymphocytic sialadenitis; NSCS, non-specific chronic sialadenitis.

Similarly, we attempted to clarify whether a Chisholm and Mason grade 3 ( 1 focus $/ 4 \mathrm{~mm}^{2}$ ) or 4 ( $>1$ focus $/ 4 \mathrm{~mm}^{2}$ ) may reflect any differences in the cytokine pattern of pSS patients, compared to grade 0 (normal MSG) or 1 and 2 (NSCS) (Fig. 3A). We observed that pSS patients with Chisholm and Mason grade 4 displayed higher levels of all the assessed cytokines when compared to subjects with Chisholm and Mason grade 0 (all $p<0.0001$ ). Furthermore, pSS patients with a Chisholm and Mason grade 4 displayed higher levels of all cytokines when compared to both Chisholm and Mason grades 1 and 2 (all $p<$ 0.05). CXCR4, CXCR5, and CCR7 were the only cytokines found to be higher in pSS patients with Chisholm and Mason grade 4 compared to pSS patients with Chisholm and Mason grade 3 (all $p<0.05$ ).

Then we divided pSS patients according to Tarpley score and observed that patients with Tarpley score $\geq 1$ displayed higher levels of all the assessed cytokines when compared to subjects with Tarpley score 0 . Moreover, pSS patients with massive 
A

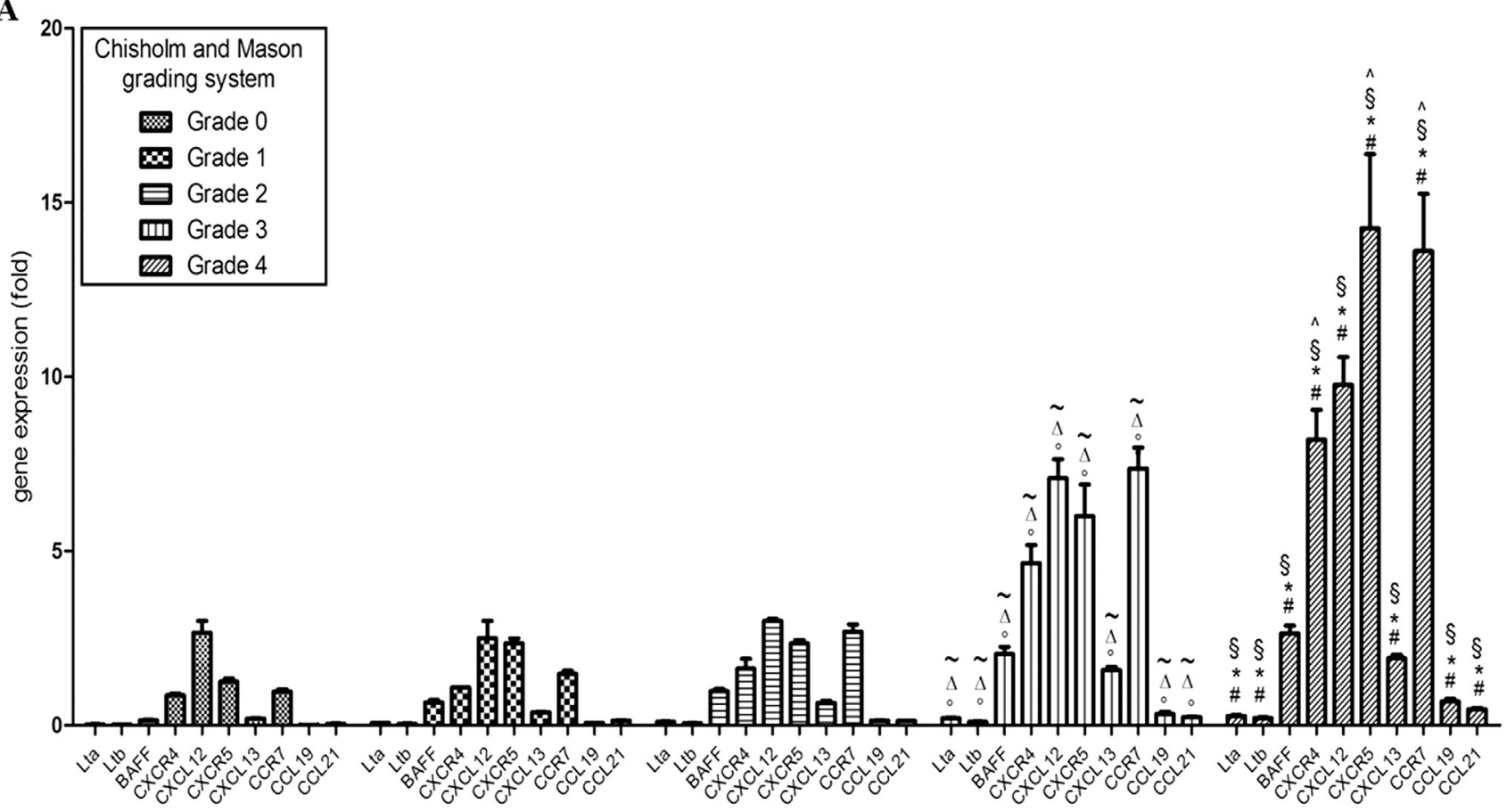

\section{B}

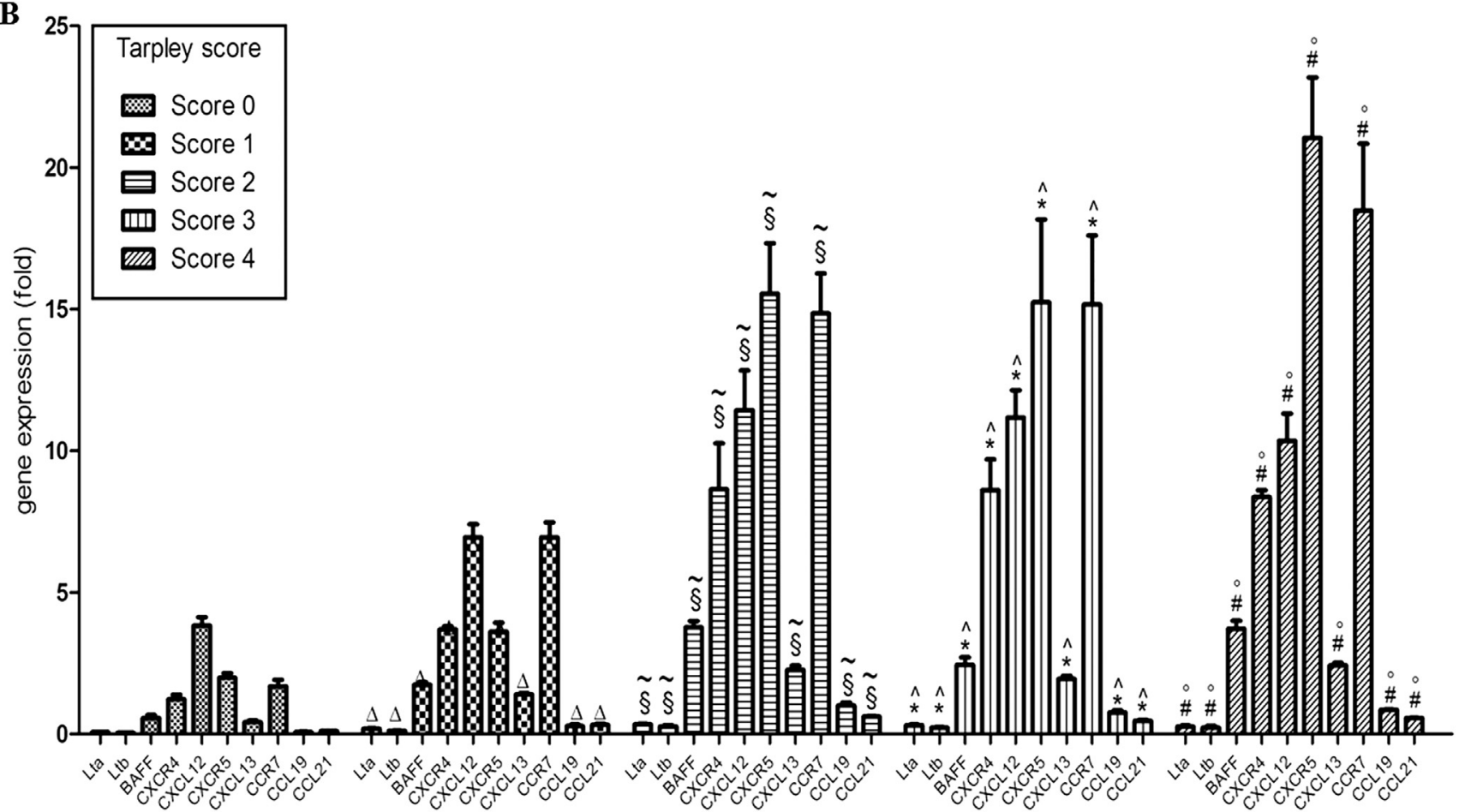

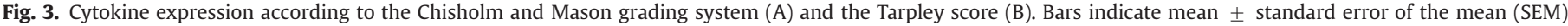

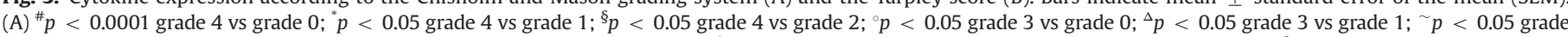

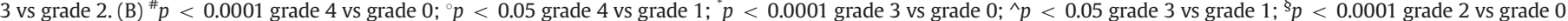

$\sim p<0.05$ grade 2 vs grade $1 ;{ }^{\Delta} p<0.05$ grade 1 vs grade 0 . Data analysis was performed with Kruskall-Wallis test and Dunn's test for multiple comparison.

derangement of glandular architecture (Tarpley score 4) displayed higher levels of all the tested cytokines, when compared to those with minimum glandular damage (Tarpley score 1). Of interest, pSS patients with Tarpley score 2 displayed higher levels of all the cytokines (all $p<0.05$ ) compared to Tarpley score 1 and those with Tarpley score 3 displayed higher levels of all cytokines compared to Tarpley score 1 (all $p<0.05$ ) (Fig. 3B). No differences were observed between patients with Tarpley scores 2, 3, and 4 .

Finally, we analyzed the cytokine pattern of pSS patients according to the presence or absence of GCs and observed that all cytokines were more expressed in samples displaying GC-like structures compared to those without GCs (all $p<0.001$; Fig. 4). 


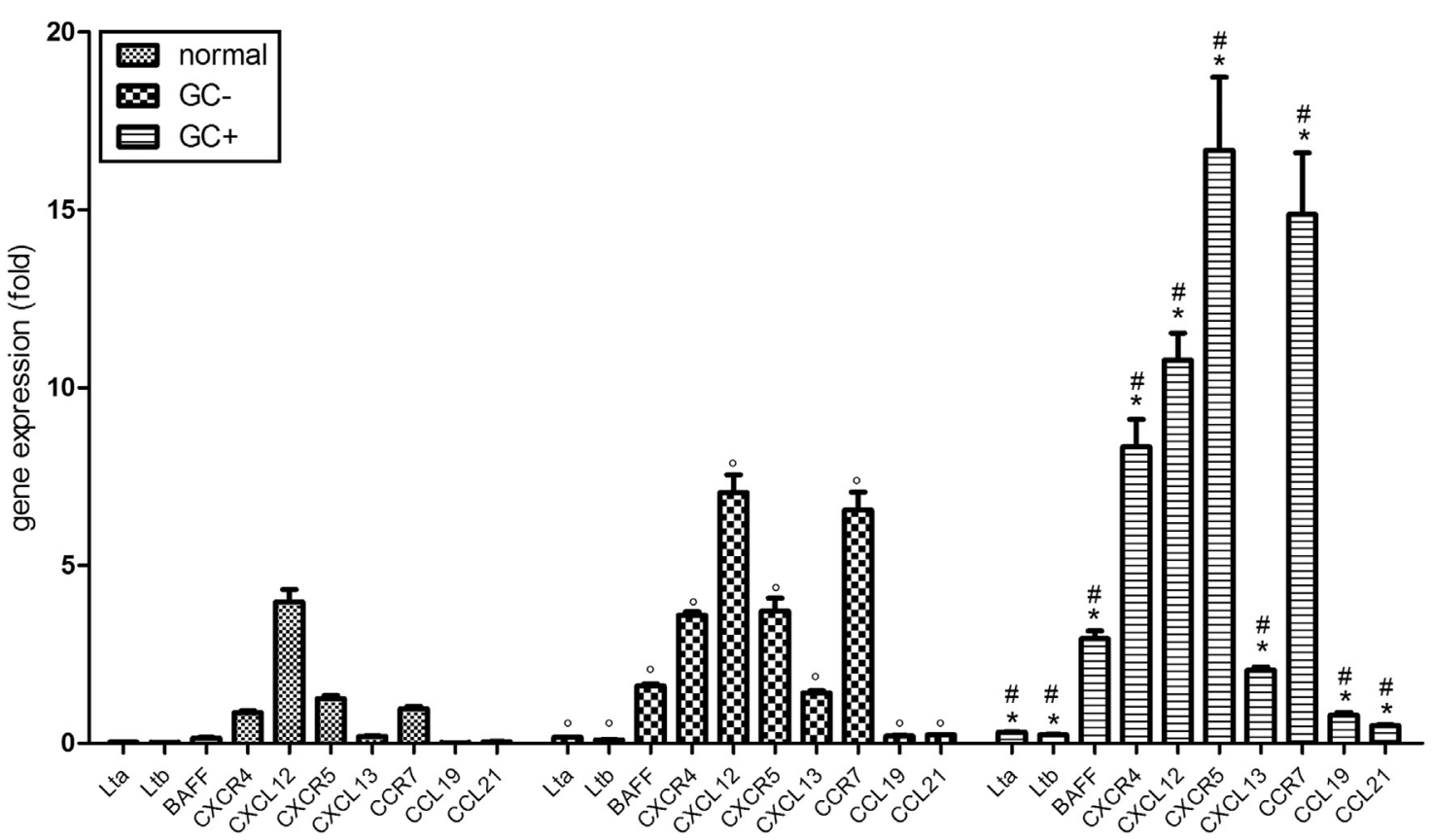

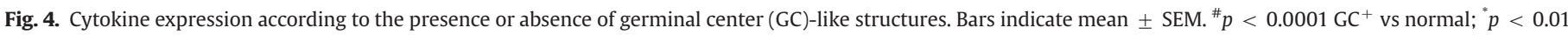
$\mathrm{GC}^{+}$vs GC${ }^{-} ;{ }^{\circ} p<0.05 \mathrm{GC}^{-}$vs normal. Data analysis was performed with Kruskall-Wallis test and Dunn's test for multiple comparison.

\section{Discussion}

Glandular inflammatory infiltrate and ectopic lymphoneogenesis, occurring in MSGs of patients with pSS, represent a powerful tool to shed some light on pSS pathogenesis. Furthermore, the identification of a relationship between histological features and clinical picture may help to predict both disease evolution and prognosis. In the present study, we assessed several specific histological, molecular, clinical, and serological features in a large cohort of pSS patients and subsequently, by multivariate analysis, we compared these pSS features in order to identify biomarkers potentially helpful in a clinical setting.

To date, MSG biopsy represents the "gold standard" for pSS diagnosis. Although it is an invasive intervention, it is an easy procedure and complications are rarely reported. Besides pSS, MSG biopsy has been employed for the diagnosis of other systemic disorders, such as amyloidosis, sarcoidosis, IgG4-related disease, and neonatal hemochromatosis [55]. The presence of FLS with a focus score $\geq 1$ in glandular tissue is a major criterion that allows pSS diagnosis. Indeed, MSG biopsy has proven to have a high specificity and positive predictive value, with a sensitivity ranging from $63.5 \%$ to $93.7 \%$ [13]. These peculiar features make MSG biopsy particularly helpful to evaluate patients with non-specific clinical manifestations, extraglandular involvement, very early disease, and/or autoantibodies negativity.

Several histological scores have been reported in literature to describe the glandular involvement during pSS. However, although the presence of foci is a hallmark of the disease, different patterns based on the quantification of inflammatory infiltrate may be observed. Moreover, the amount of the inflammatory infiltrate appeared to correlate with several demographic, clinical, and serological features [56].

The Chisholm and Mason grading system considers MSGs with normal architecture (grade 0), slight and moderate infiltrate (grades 1 and 2, respectively), presence of 1 focus (grade 3 ), and more than 1 focus in $4 \mathrm{~mm}^{2}$ [6]. The Tarpley score highlights only the absence (score 0 ) or the presence (scores 1-4) of foci in $4 \mathrm{~mm}^{2}$ of glandular tissue, with the higher scores identifying glands with many foci and consequent progressive derangement of glandular tissue [7]. Finally, in order to assess and quantify the presence of inflammatory cells, some authors proposed an inflammatory severity score including (i) normal MSGs (score 1), (ii) MSGs with different amounts of inflammatory cells (scores 2-4), and (iii) the presence of 1 or more foci in $4 \mathrm{~mm}^{2}$ (score 5) [8-10]. The main limitations of these classical score systems is to be confined to the diagnostic setting, and H\&E staining allows only to quantify the inflammatory infiltrate and foci number, without giving information concerning qualitative features of the infiltrate. Therefore, we speculated that a molecular approach on one hand and different histological techniques such as immunofluorescence and immunochemistry on the other may provide the clinicians with a wide range of additional information for each pSS patient.

To reach this goal, we performed these 2 approaches, at the same time, and attempted to find a rationale for their employment in clinical practice. Previous studies were aimed to identify the prevalence of GCs in pSS patients, reporting percentages ranging from $18 \%$ to $59 \%$ [23]. However, the prevalence of $\mathrm{GC}^{+}$patients in our cohort was $56 \%$, of the total number of patients reported, and it was higher than those reported in available literature. Such discrepancy may be due to the different histological approach of our study, which was based not only on H\&E staining, but evaluating the B-/T-cells compartmentalization, together with the possible presence of $\mathrm{CD} 21^{+}$cells, in the inflammatory infiltrate, by immunofluorescence. From a clinical point of view, our data show that ectopic GC formation in exocrine glands is associated with a more severe disease, and $\mathrm{GC}^{+}$patients are diagnosed with pSS at a younger age. Indeed, $\mathrm{GC}^{+}$patients experienced more frequently extraglandular manifestations, salivary gland swelling, hypergammaglobulinemia, and autoantibody production, when compared to $\mathrm{GC}^{-}$patients. Therefore, it is conceivable that these patients, with a more severe disease, refer to the rheumatologists earlier than patients with mild clinical manifestations, who do not display GC. To note, the evidence that extraglandular involvement was independently associated to GC presence, at multivariate analysis, is in line with previous reports and appears to confirm the link between ectopic lymphoneogenesis and a more severe clinical picture. 
Furthermore, in our patients, the presence of GCs was associated with a more severe glandular involvement as suggested by both higher focus score and higher histopathological scores.

Taking into account the pivotal role of GCs in driving B- and Tcell activation, it has been suggested that their presence in the pSS glandular infiltrates may affect the clinical picture and the progression of the disease in several ways [57]: (i) the higher degree of lymphocytic organization may lead to a more pronounced disruption of glandular architecture and secretory function impairment [31,58]; (ii) GC formation may increase lymphocyte activation and function, autoantibody production [57], and immune complex formation, leading to extraglandular manifestations [57-59]; and (iii) the development of B-cell NHL seems to rely on antigen-driven stimulation [60].

Ectopic lymphoid tissue represents a common finding in several autoimmune diseases, such as RA and pSS, where synovium, exocrine glands, and other tissues are chronically inflamed. The formation of GC-like structures is the result of a multi-step dynamic process involving immune cells, epithelial cells, high endothelial venules, chemokines, cytokines, growth factors, and related receptors. In particular, evidence from animal models and pSS patients showed that the formation and maintenance of tertiary lymphoid tissues is critically dependent on the ectopic expression of Lt $\alpha$ and Lt $\beta$, CXCL13, CXCL12, CCL19, and CCL21, as well as their interaction with specific receptors, CXCR5, CXCR4, and CCR7, respectively $[17,42]$. In addition, BAFF is involved in B-cell survival and humoral immune responses, playing a critical role in B-cell homeostasis [36].

Therefore, in patients developing GC-like infiltrates, a different genetic, serological, and glandular cytokine profile is detectable compared to those without GC structures or healthy controls [24-27].

In our study, a subgroup of 50 patients with clinical, serological, and histopathological features overlapping that of the global study cohort, were evaluated to quantify the expression of chemokines, cytokines, and related receptors, involved in glandular inflammatory process and lymphoneogenesis at mRNA level. Our results mirror what is already observed in the aforementioned studies, since we observed higher levels of Lt $\alpha$, Lt $\beta$, BAFF, CXCR4, CXCL12, CXCR5, CXCL13, CCR7, CCL19, and CCL21 in FLS MSGs when compared to normal MSGs or NSCS patterns. However, we show, for the first time, a global overview concerning many of the key cytokines involved in pSS pathogenesis, pointing out their reciprocal correlation and the association with MSG involvement.

On this basis, the presence of FLS, and consequently the ectopic lymphoid tissue, seems to be strictly related to, and dependent on, the expression of inflammatory cytokines such as Lt $\alpha$ and Lt $\beta$; the activation CXCL12/CXCR4, CXCL13/CXCR5, and CCR7/CCL19-CCL21 pathways; and the evidence of higher amounts of BAFF.

To note, a similar behavior was observed when patients were stratified according to other histological score systems such as the severity of inflammatory infiltrate, the Chisholm and Mason grading system, and the Tarpley score. In particular, we showed that the worse was the inflammatory infiltrate, the higher were the value of histological score and the levels of molecular expression. These findings point out that the increasing severity of the histological pattern and the organization of the inflammatory infiltrate parallel the increasing amounts of the assessed cytokine profile. Noteworthy, when we stratified patients according to the presence or absence of GC, we observed that $\mathrm{GC}^{+}$patients displayed higher levels of Lt $\alpha$, Lt $\beta$, BAFF, CXCR4, CXCL12, CXCR5, CXCL13, CCR7, CCL19, and CCL21 when compared to $\mathrm{GC}^{-}$patients. These data confirm the role of these cytokines in the formation of ectopic GC-like structures, B-/T-cell compartmentalization, and fDCs recruitment.

Furthermore, patients who developed GC-like infiltrates displayed not only a different clinical and serological profile, but also a different histological and glandular cytokine profile, when compared to those without GC structures or healthy controls.

These findings deserve some consideration from a therapeutic point of view. We recently correlated the clinical response to the immune-histological and molecular patterns in a large cohort of pSS patients treated with a chimeric humanized monoclonal antiCD20 antibody (rituximab; RTX) [61]. We showed that this therapy is able to interfere with the formation of tertiary lymphoid tissue, not only depleting B-cells, but also tuning the delicate equilibrium between cells, molecules, and receptors, partially affecting the proB-cell inflammatory milieu that is typical of the inflamed glands. In particular, MSGs of pSS patients treated with RTX showed the higher rate of GC disappearance, and this datum was correlated with a decrease of the expression at mRNA level of CXCR4 and CXCR5 in the samples from the affected glands, which mirrored the lack of $\mathrm{CXCR} 4^{+}$and $\mathrm{CXCR} 5^{+}$cells in the infiltrates. Furthermore, an increased level of CXCL12 and CXCL13, without any effect concerning the BAFF expression, was also reported.

\section{Conclusion}

Our study provides evidence that different histopathological features and scoring reflect different degrees of inflammation and cytokine expression on one hand, and different clinical patterns, including autoantibodies production and extraglandular involvement, on the other. In order to improve in clinical practice the classical histopathological report, it may be helpful to include more detailed information concerning the focus score, such as B-/T-cell compartmentalization and GC presence, to support clinicians in planning their diagnostic and therapeutic approach. Furthermore, we confirmed that BAFF, LT $\alpha$ and LT $\beta$, CXCR4/CXCL12, CXCR5/CXCL13, and CCR7/CCL19-CCL21 axis play a pivotal role in chronic activation of the immune system, leading to GC formation and probably are involved in disease progression and development of severe complications.

\section{Acknowledgments}

The authors are grateful to Dr. Vittorio Bini for the assistance with statistical analysis.

\section{Appendix A. Supplementary Information}

Supplementary data associated with this article can be found in the online version at http://dx.doi.org/10.1016/j.semarthrit.2014. 05.015 .

\section{References}

[1] Mavragani CP, Nezos A, Moutsopoulos HM. New advances in the classification, pathogenesis and treatment of Sjogren's syndrome. Curr Opin Rheumatol 2013;25:623-9.

[2] Nocturne G, Mariette X. Advances in understanding the pathogenesis of primary Sjögren's syndrome. Nat Rev Rheumatol 2013;9:544-56.

[3] Quartuccio L, Isola M, Baldini C, Priori R, Bartoloni Bocci E, Carubbi F, et al Biomarkers of lymphoma in Sjögren's syndrome and evaluation of the lymphoma risk in prelymphomatous conditions: results of a multicenter study. J Autoimmun 2013. http://dx.doi.org/10.1016/j.jaut.2013.10.002.

[4] Greenspan JS, Daniels TE, Talal N, Sylvester RA. The histopathology of Sjogren's syndrome in labial salivary gland biopsies. Oral Surg Oral Med Oral Pathol 1974;37:217-29.

[5] Daniels TE. Labial salivary gland biopsy in Sjögren's syndrome: assessment as a diagnostic criterion in 362 suspected cases. Arthritis Rheum 1984;27: 147-56.

[6] Chisholm DM, Mason DK. Labial salivary gland biopsy in Sjögren's disease. J Clin Pathol 1968:21:656-60. 
[7] Tarpley TM, Anderson LG, White CL. Minor salivary gland involvement in Sjogren's syndrome. Oral Surg Oral Med Oral Pathol 1974;37:64-74.

[8] Daniels TE, Whitcher JP. Association of patterns of labial salivary gland inflammation with keratoconjunctivitis sicca. Analysis of 618 patients with suspected Sjögren's syndrome. Arthritis Rheum 1994;37:869-77.

[9] Liquidato BM, SolerRde C, BussolotiFilho I. Evaluation of the concordance of sialometry and salivary glands scintigraphy in dry mouth patients. Braz J Otorhinolaryngol 2006;72:116-9.

[10] Liquidato BM, Duarte Barros M, Bussoloti Filho I, Pereira CSB, Macéa MIM. Minor salivary glands morphology in xerostomia patients. Int J Morphol 2006;24:489-93.

[11] Vitali C, Bombardieri S, Jonsson R, Moutsopoulos HM, Alexander EL, Carsons SE, et al. Classification criteria for Sjögren's syndrome: a revised version of the European criteria proposed by the American-European Consensus Group. Ann Rheum Dis 2002;61:554-8.

[12] Shiboski SC, Shiboski CH, Criswell L, Baer A, Challacombe S, Lanfranchi H, et al. American College of Rheumatology classification criteria for Sjögren's syndrome: a data-driven, expert consensus approach in the Sjögren's International Collaborative Clinical Alliance cohort. Arthritis Care Res 2012;64: 475-87.

[13] Guellec D, Cornec D, Jousse-Joulin S, Marhadour T, Marcorelles P, Pers JO, et al. Diagnostic value of labial minor salivary gland biopsy for Sjögren's syndrome: a systematic review. Autoimmun Rev 2013;12:416-20.

[14] Christodoulou MI, Kapsogeorgou EK, Moutsopoulos HM. Characteristics of the minor salivary gland infiltrates in Sjögren's syndrome. J Autoimmun 2010;34:400-7.

[15] Kapsogeorgou EK, Christodoulou MI, Panagiotakos DB, Paikos S, Tassidou A, Tzioufas AG, et al. Minor salivary gland inflammatory lesions in Sjogren syndrome: do they evolve? J Rheumatol 2013;40:1566-71.

[16] Zhou D, Chen YT, Chen F, Gallup M, Vijmasi T, Bahrami AF, et al. Critical involvement of macrophage infiltration in the development of Sjögren's syndrome-associated dry eye. Am J Pathol 2012;181:753-60.

[17] Aloisi F, Pujol-Borrell R. Lymphoid neogenesis in chronic inflammatory diseases. Nat Rev Immunol 2006;6:205-17.

[18] Bombardieri M, Barone F, Humby F, Kelly S, McGurk M, Morgan P, et al. Activation induced cytidine deaminase expression in follicular dendritic cell networks and interfollicular large B cells supports functionality of ectopic lymphoid neogenesis in autoimmune sialadenitis and MALT lymphoma in Sjogren's syndrome. J Immunol 2007;179:4929-38.

[19] Salomonsson S, Jonsson MV, Skarstein K, Brokstad KA, Hjelmström P, WahrenHerlenius M, et al. Cellular basis of ectopic germinal center formation and autoantibody production in the target organ of patients with Sjögren's syndrome. Arthritis Rheum 2003;48:3187-201.

[20] Halse A-K, Marthinussen MC, Wahren-Herlenius M, Jonsson R. Isotype distribution of anti-Ro/SS-A and anti-La/SS-B antibodies in plasma and saliva of patients with Sjögren's syndrome. Scand J Rheumatol 2000;29:13-9.

[21] Jonsson MV, Skarstein K, Jonsson R, Brun JG. Serological implications of germinal center-like structures in primary Sjögren's syndrome. J Rheumatol 2007;34:2044-9.

[22] Theander E, Vasaitis L, Baecklund E, Nordmark G, Warfvinge G, Liedholm R, et al. Lymphoid organisation in labial salivary gland biopsies is a possible predictor for the development of malignant lymphoma in primary Sjögren's syndrome. Ann Rheum Dis 2011;70:1363-8.

[23] Risselada AP, Looije MF, Kruize AA, Bijlsma JW, van Roon JA. The role of ectopic germinal centers in the immunopathology of primary Sjögren's syndrome: a systematic review. Semin Arthritis Rheum 2013;42:368-76.

[24] Szodoray P, Alex P, Jonsson MV, Knowlton N, Dozmorov I, Nakken B, et al. Distinct profiles of Sjögren's syndrome patients with ectopic salivary gland germinal centers revealed by serum cytokines and BAFF. Clin Immunol 2005; $117: 168-76$

[25] Reksten TR, Jonsson MV, Szyszko EA, Brun JG, Jonsson R, Brokstad KA. Cytokine and autoantibody profiling related to histopathological features in primary Sjogren's syndrome. Rheumatology (Oxford) 2009;48:1102-6.

[26] Le Pottier L, Devauchelle V, Fautrel A, Daridon C, Saraux A, Youinou P, et al. Ectopic germinal centers are rare in Sjogren's syndrome salivary glands and do not exclude autoreactive B cells. J Immunol 2009;182:3540-7.

[27] Reksten TR, Johnsen SJ, Jonsson MV, Omdal R, Brun JG, Theander E, et al. Genetic associations to germinal centre formation in primary Sjogren's syndrome. Ann Rheum Dis 2013 . doi:annrheumdis-2012-202500.

[28] Youinou P, Pers JO. Disturbance of cytokine networks in Sjogren's syndrome. Arthritis Res Ther 2011;13:227.

[29] Alunno A, Bistoni O, Bartoloni E, Caterbi S, Bigerna B, Tabarrini A, et al. IL-17producing CD4-CD8-T cells are expanded in the peripheral blood, infiltrate salivary glands and are resistant to corticosteroids in patients with primary Sjogren's syndrome. Ann Rheum Dis 2013;72:286-92.

[30] Ciccia F, Guggino G, Giardina A, Ferrante A, Carubbi F, Giacomelli R, et al. The role of innate and lymphoid IL-22-producing cells in the immunopathology of primary Sjogren's syndrome. Expert Rev Clin Immunol 2014;10:533-41.

[31] Alunno A, Petrillo MG, Bistoni O, Bartoloni E, Caterbi S, Bianchini R, et al. Characterization of a new regulatory CD4 + T-cell subset in primary Sjögren's syndrome. Rheumatology (Oxford) 2013;52:1387-96.

[32] Christodoulou MI, Kapsogeorgou EK, Moutsopoulos NM, Moutsopoulos HM. Foxp3 + T-regulatory cells in Sjogren's syndrome: correlation with the grade of the autoimmune lesion and certain adverse prognostic factors. Am J Pathol 2008:173:1389-96.
[33] Alunno A, Carubbi F, Bistoni O, Caterbi S, Bartoloni E, Bigerna B, et al. CD4CD8-T-cells in primary Sjögren's syndrome: association with the extent of glandular involvement. J Autoimmun 2014. http://dx.doi.org/10.1016/j. jaut.2014.01.030

[34] Cornec D, Devauchelle-Pensec V, Tobón GJ, Pers JO, Jousse-Joulin S, Saraux A. B cells in Sjögren's syndrome: from pathophysiology to diagnosis and treatment. J Autoimmun 2012;39:161-7.

[35] Routsias JG, Goules JD, Charalampakis G, Tzima S, Papageorgiou A, Voulgarelis M. Malignant lymphoma in primary Sjögren's syndrome: an update on the pathogenesis and treatment. Semin Arthritis Rheum 2013;43:178-86.

[36] Moisini I, Davidson A. BAFF: a local and systemic target in autoimmune diseases. Clin Exp Immunol 2009;158:155-63.

[37] Thien M, Phan TG, Gardam S, Amesbury M, Basten A, Mackay F, et al. Excess BAFF rescues self-reactive B cells from peripheral deletion and allows them to enter forbidden follicular and marginal zone niches. Immunity 2004;20: 785-98.

[38] Groom J, Kalled SL, Cutler AH, Olson C, Woodcock SA, Schneider P, et al Association of BAFF/BLyS overexpression and altered B cell differentiation with Sjogren's syndrome. J Clin Invest 2002;109:59-68.

[39] Lavie F, Miceli-Richard C, Quillard J, Roux S, Leclerc P, Mariette X. Expression of BAFF (BLyS) in T cells infiltrating labial salivary glands from patients with Sjogren's syndrome. J Pathol 2004;202:496-502.

[40] Pers JO, Daridon C, Devauchelle V, Jousse S, Saraux A, Jamin C, et al. BAFF overexpression is associated with autoantibody production in autoimmune diseases. Ann N Y Acad Sci 2005;1050:34-9.

[41] Mariette X, Roux S, Zhang J, Bengoufa D, Lavie F, Zhou T, et al. The level of BLyS (BAFF) correlates with the titre of autoantibodies in human Sjogren's syndrome. Ann Rheum Dis 2003;62:168-71.

[42] Corsiero E, Bombardieri M, Manzo A, Bugatti S, Uguccioni M, Pitzalis C. Role of lymphoid chemokines in the development of functional ectopic lymphoid structures in rheumatic autoimmune diseases. Immunol Lett 2012;145:62-7.

[43] Van de Pavert SA, Mebius RE. New insights into the development of lymphoid tissues. Nat Rev Immunol 2010;10:664-74.

[44] Barone F, Bombardieri M, Manzo A, Blades MC, Morgan PR, Challacombe SJ et al. Association of CXCL13 and CCL21 expression with the progressive organization of lymphoid-like structures in Sjogren's syndrome. Arthritis Rheum 2005:52:1773-84.

[45] Amft N, Curnow SJ, Scheel-Toellner D, Devadas A, Oates J, Crocker J, et al Ectopic expression of the B cell-attracting chemokine BCA-1 (CXCL13) on endothelial cells and within lymphoid follicles contributes to the establish ment of germinal center-like structures in Sjogren's syndrome. Arthritis Rheum 2001;44:2633-41.

[46] Xanthou G, Polihronis M, Tzioufas AG, Paikos S, Sideras P, Moutsopoulos HM. 'Lymphoid' chemokine messenger RNA expression by epithelial cells in the chronic inflammatory lesion of the salivary glands of Sjögren's syndrome patients. Possible participation in lymphoid structure formation. Arthritis Rheum 2001:44:408-18.

[47] Salomonsson S, Larsson P, Tengnér P, Mellquist E, Hjelmström P, WahrenHerlenius M. Expression of the B cell-attracting chemokine CXCL13 in the target organ and autoantibody production in ectopic lymphoid tissue in the chronic inflammatory disease Sjögren's syndrome. Scand J Immunol 2002;55:336-42.

[48] Barone F, Bombardieri M, Rosado MM, Morgan PR, Challacombe SJ, De Vita S, et al. CXCL13, CCL21, and CXCL12 expression in salivary glands of patients with Sjogren's syndrome and MALT lymphoma: association with reactive and malignant areas of lymphoid organization. J Immunol 2008;180:5130-40.

[49] Hansen A, Reiter K, Ziprian T, Jacobi A, Hoffmann A, Gosemann M, et al Dysregulation of chemokine receptor expression and function by B cells of patients with primary Sjögren's syndrome. Arthritis Rheum 2005;52: 2109-19.

[50] Hansen A, Lipsky PE, Dörner T. B cells in Sjögren's syndrome: indications for disturbed selection and differentiation in ectopic lymphoid tissue. Arthritis Res Ther 2007;9:218.

[51] Bombardieri M, Barone F, Lucchesi D, Nayar S, van den Berg WB, Proctor C, et al. Inducible tertiary lymphoid structures, autoimmunity, and exocrine dysfunction in a novel model of salivary gland inflammation in C57BL/6 mice. J Immunol 2012;189:3767-76.

[52] Link A, Vogt TK, Favre S, Britschgi MR, Acha-Orbea H, Hinz B, et al. Fibroblastic reticular cells in lymph nodes regulate the homeostasis of naive $\mathrm{T}$ cells. Nat Immunol 2007;8:1255-65.

[53] Ishimaru N, Yamada A, Nitta T, Arakaki R, Lipp M, Takahama Y, et al. CCR7 with S1P1 signaling through AP-1 for migration of Foxp3 + regulatory T-cells controls autoimmune exocrinopathy. Am J Pathol 2012;180:199-208.

[54] Pereira JP, Kelly LM, Cyster JG. Finding the right niche: B-cell migration in the early phases of T-dependent antibody responses. Int Immunol 2010;22: 413-9.

[55] Varela-Centelles P, Sanchez-Sanchez M, Seoane J. Lip biopsy for the diagnosis of Sjögren's syndrome: beware of the punch. Int J Oral Maxillofac Surg 2013 http://dx.doi.org/10.1016/j.ijom.2013.05.014.

[56] Gerli R, Muscat C, Giansanti M, Danieli MG, Sciuto M, Gabrielli A, et al. Quantitative assessment of salivary gland inflammatory infiltration in primary Sjögren's syndrome: its relationship to different demographic, clinical and serological features of the disorder. Br J Rheumatol 1997;36:969-75.

[57] Vinuesa CG, Sanz I, Cook MC. Dysregulation of germinal centres in autoimmune disease. Nat Rev Immunol 2009;9:845-57. 
[58] Daniels TE, Cox D, Shiboski CH, Schiødt M, Wu A, Lanfranchi H, et al. Associations between salivary gland histopathologic diagnoses and phenotypic features of Sjögren's syndrome among 1,726 registry participants. Arthritis Rheum 2011;63:2021-30.

[59] Voulgarelis M, Tzioufas AG. Pathogenetic mechanisms in the initiation and perpetuation of Sjögren's syndrome. Nat Rev Rheumatol 2010;6: 529-37.
[60] Bahler DW, Miklos JA, Swerdlow SH. Ongoing Ig gene hypermutationin salivary gland mucosa-associated lymphoid tissue type lymphomas. Blood 1997;89:3335-44.

[61] Carubbi F, Cipriani P, Marrelli A, Benedetto P, Ruscitti P, Berardicurti O, et al. Efficacy and safety of rituximab treatment in early primary Sjögren's syndrome: a prospective, multi-center, follow-up study. Arthritis Res Ther 2013;15:R172, http://dx.doi.org/10.1186/ar4359. 